\title{
Variations of Steroid Hormone Metabolites in Serum and Urine in Polycystic Ovary Syndrome after Nafarelin Stimulation: Evidence for an Altered Corticoid Excretion*
}

\author{
PETER LUPPA, BURKHARDT MÜIIIER, KARL JACOB, RAINER KIMMIG, \\ THOMAS STROWITZKI, CORNELIA HOSS, MICHAEL M. WEBER, \\ DIETER ENGELHARDT, AND ROGERIO A. LOBO
}

Institut für Klinische Chemie und Pathobiochemie (P.L., B.M.) and Frauenklinik (C.H.), Klinikum rechts der Isar, Technical University Munich; Institut für Klinische Chemie (K.J.), Frauenklinik (R.K., T.S.), and Medizinische Klinik II (M.M.W., D.E.), Klinikum Grosshadern, Ludwig-Maximilians University Munich, Munich, Germany; and the University of Southern California School of Medicine (R.A.L.), Los Angeles, California 90033

\begin{abstract}
To evaluate the clinical relevance of testing pituitary-ovarian responses in patients suffering from polycystic ovary syndrome (PCOS) with the GnRH agonist nafarelin, a 1.2-mg dose of nafarelin was given intranasally to 19 women with PCOS and 15 healthy premenopausal women. The subsequent analysis of steroids in both serum and urine during the test was carried out at several time points for up to $24 \mathrm{~h}$.

Serum levels of $17 \alpha$-hydroxyprogesterone were elevated at all time points of the test in PCOS patients $v$ s. controls [at baseline, $3.5 \pm 0.2$ vs. $1.8 \pm 0.1 \mathrm{nmol} / \mathrm{L}(P<0.001)$; at $24 \mathrm{~h}, 9.9 \pm 0.9$ vs. $4.9 \pm$ $0.3 \mathrm{nmol} / \mathrm{L}(P<0.001)]$. Basal levels of androstenedione were higher in the patient group, but there was no significant change during the test in either group. Serum testosterone levels were also found to differ in PCOS patients compared with the control values at baseline ( 2.2 \pm 0.2 vs. $1.5 \pm 0.1 \mathrm{nmol} / \mathrm{L} ; P<0.05$ ) and after nafarelin treatment (at $24 \mathrm{~h}, 3.2 \pm 0.4$ vs. $1.8 \pm 0.2 \mathrm{nmol} / \mathrm{L} ; P<0.05$ ). Serum estradiol levels rose significantly in both groups during the test; the posttest levels were significantly higher in PCOS than in controls.
\end{abstract}

The PCOS patients displayed a significant increase in androgen and gestagen metabolites as well as in glucocorticoid metabolites excreted in the urine during the $24 \mathrm{~h}$. In the control subjects, except for $17 \alpha$-hydroxypregnanolone, which rose significantly, none of the urinary steroids investigated showed relevant changes during the nafarelin test. The posttest excretion of allo-tetrahydrocortisol (1.4 \pm 0.2 vs. $0.3 \pm 0.1 \mu \mathrm{mol} / \mathrm{g}$ creatinine; $P<0.001$ ) and the increase in $17 \alpha$-hydroxypregnanolone excretion $(1.4 \pm 0.2 \mathrm{vs} .0 .3 \pm 0.1 \mu \mathrm{mol} / \mathrm{g}$ creatinine; $P<0.001$ ) were distinctly higher in PCOS patients than in the controls; the diagnostic sensitivity of the combination of both parameters was $89 \%$ at a $93 \%$ specificity. Thus, measurements of $17 \alpha$-hydroxyprogesterone levels in serum and of urinary allo-tetrahydrocortisol and $17 \alpha$-hydroxypregnanolone after nafarelin treatment make this stimulation test a valuable diagnostic tool for identifying PCOS patients. The significant changes in the excretion of urinary androgen and gestagen metabolites, unmasked by $\mathrm{GnRH}$ agonist stimulation, suggest a functional alteration of the pituitaryovarian axis. The reason for the increased excretion of glucocorticoid metabolites after nafarelin stimulation remains to be clarified. $(\mathrm{JClin}$ Endocrinol Metab 80: 280-288, 1995)
Po OLYCYSTIC ovary syndrome (PCOS) is an endocrinopathy commonly associated with menstrual irregularities; anovulatory infertility; skin manifestations such as

Received July 15, 1994. Revision received September 20, 1994. Accepted September 23, 1994.

Address all correspondence and requests for reprints to: Dr. P. Luppa, Institut für Klinische Chemie \& Pathobiochemie, Klinikum rechts der Isar der TU München, Ismaninger Str. 22, D-81675 Munich, Germany.

* This work was supported by the Friedrich-Baur-Stiftung (Munich, Germany).

A: androstenedione (androst-4-ene-3,17-dione); AD: androstanediol ( $3 \alpha, 17 \beta$-dihydroxy- $5 \alpha$-androstane); ADG: androstane-diol glucuronide

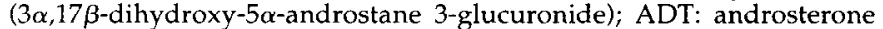
( $3 \alpha$-hydroxy- $5 \alpha$-androstan-17-one); ADTG: androsterone glucuronide

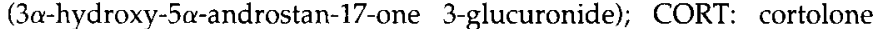
$(3 \alpha, 17 \alpha, 20 \alpha, 21$-tetrahydroxy-5 $\beta$-pregan-11-one); $\beta$ CORT: $\beta$-cortolone ( $3 \alpha, 17 \alpha, 20 \alpha, 21$-tetrahydroxy-5 $\beta$-pregnan-11-one); DHEA: dehydroepiandrosterone ( $3 \beta$-hydroxyandrost-5-en-17-one); DHEAS: dehydroepiandrosterone-sulfate ( $3 \beta$-hydroxyandrost-5-en-17-one 3-sulfate); E: cortisone (17 $\alpha, 21$-dihydroxypregn-4-ene-3, 11, 20-trione); E2: 17 $\beta$-estradiol (3, $17 \beta$-dihydroxyestra- $1,3,5(10)$-triene); ET: $3 \alpha$-etiocholanolone ( $3 \alpha$ hydroxy-5 $\beta$-androstan-17-one); $F$ : cortisol $(11 \beta, 17 \alpha, 21$ trihydroxypregn-4-ene-3, 20-dione); FAI: free androgen index; IRMA: immunora- acne, alopecia, or hirsutism; hyperinsulinemia; and obesity (1-5). The syndrome is clinically heterogeneous, exhibiting a broad spectrum of phenotypes $(4,5)$. The diagnosis of PCOS has been made by histological identification of multiple follicular cysts and thecal cell hyperplasia (2), usually in enlarged ovaries (4), although this is not a requirement for the clinical diagnosis. Polycystic ovaries are easily recognized by ultrasound, but as they are found in other disorders as well as in normal women, the finding of polycystic ovaries alone is not sufficient to make the diagnosis of PCOS.

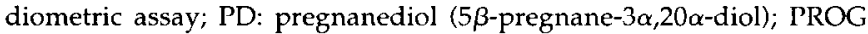
progesterone (pregn-4-ene-3,20-dione)-; 17HPROG: (17 $\alpha$-hydroxyprogesterone (17 $\alpha$-hydroxypregn-4-ene-3,20-dione); 17HPREG: $17 \alpha$-hydroxy-pregnanolone $(3 \alpha, 17 \alpha$, dilhydroxy-5 $\beta$-pregnan20-one); PT: $(3 \alpha$, $17 \alpha, 20 \alpha$-trihydroxy-5 $\beta$-pregnane); RIA: radioimmunoassay; SHBG: sex hormone-binding globulin T: testosterone (17 $\beta$-hydroxyandrost-4-en-3one); THE: tetrahydrocortisone $(3 \alpha, 17 \alpha, 21$-trihydroxy- $5 \beta$-pregnane11,20-dione; THF: tetrahydrocortisol $(3 \alpha, 11 \beta, 17 \alpha, 21$-tetrahydroxy-5 $\beta$ pregnan-20-one); aTHF: allo-tetrahydrocortisol $(3 \alpha, 11 \beta, 17 \alpha, 21$-tetrahydroxy-5 $\alpha$-pregan-20-one); THS: tetrahydro-11-deoxyxortisol $(3 \alpha, 17 \alpha$, 21 -trihydroxy- $5 \beta$-pregnan-20-one). 
The etiology of the disorder is still a subject of controversy. There are lines of evidence suggesting that PCOS is a form of functional ovarian hyperandrogenism, triggered by gonadotropin-dependent mechanisms $(6,7)$. One explanation of this phenomenon is the estrone hypothesis $(8,9)$, according to which permanent hyperestronemia is thought to sensitize the pituitary $(9,10)$ and cause an increase in LH secretion. $\Lambda$ s a result, thecal-interstitial cells are stimulated to hyperplasia, leading to an excess secretion of androstenedione (A) and other androgens. An elevation in unbound or free estradiol $\left(E_{2}\right)$ has also been suggested to be a contributory factor (11). These and other theories are not mutually exclusive. More recently, defects in different enzyme systems regulating the steroid pathway have been thought to initialize the pathophysiological conditions for PCOS. One of the underlying defects is thought to be an increase in the activity of skin and hepatic $5 \alpha$-reductase $(12,13)$, resulting in an augmented conversion of testosterone (T) to dihydrotestosterone (14). In gas chromatography steroid profiles, this results in higher ratios of $5 \alpha$-tetrahydrocortisol (aTHF) $/ 5 \beta$ tetrahydrocortisol (THF) and $5 \alpha$-androsterone ( $5 \alpha \mathrm{ADT}) /$ $5 \beta$-etio-cholanolone (5BET) in urine (14). Rodin et al. (15) found an increased adrenal secretion of cortisol due to an augmented adrenocortical activity in women with PCOS caused by increased activity of $11 \beta$-hydroxysteroid dehydrogenase $(11 \beta \mathrm{HSDH})$, entailing an altered interconversion of cortisol (F) to cortisone (E). Thus, the enhanced cortisol clearance rate brings about an increase in the synthesis of adrenal androgens. Another explanation for the functional ovarian hyperandrogenism might be a dysregulated ovarian cytochrome P450c17 $\alpha$ enzyme complex (17 $\alpha$-hydroxylase plus 17,20 lyase activity) (16). Based on this hypothesis, a specific biochemical diagnostic test for this disorder has been established by analyzing the specific stimulation of the pituitary-ovarian axis by GnRH agonists (GnRHa). Barnes $e t$ al. (6) and Ehrmann et al. (7) first used the GnRHa [6-D-(2naphthyl)alanine]GnRH (nafarelin)] to stimulate pituitary and gonadal secretion in PCOS patients. This agonist is 200fold more effective in stimulating the pituitary-gonadal axis than endogenous GnRH $(17,18)$. Compared with those in healthy individuals, women suffering from this disorder display patterns of basal and stimulated levels of serum $\mathrm{LH}$, FSH, and $17 \alpha$-hydroxyprogesterone (17HPROG) similar to those in men. A masculinized pituitary and ovarian response to a GnRHa stimulus, therefore, implies that the cytochrome P450c17 $\alpha$ enzyme complex within the ovarian thecal-interstitial cells has become hyperfunctional.

In addition to the pathological response to nafarelin and the related GnRHa buserelin (19), biochemical findings in PCOS patients normally include either an increased concentration of serum LH or an increased LH/FSH ratio $(5,20)$. Hyperandrogenemia is characteristic in the syndrome and is often reflected clinically as hirsutism. The basal serum levels of the androgens $\mathrm{T}, \mathrm{A}$, and dehydroepiandrosterone sulfate (DHEAS; suppressible with dexamethasone) are elevated (21-25). Furthermore, ADT and androstanediol glucuronides and sulfates (metabolites of dihydrotestosterone) are often found to be elevated (34-36). Hyperinsulinemia and insulin resistance are also found in both the lean and, more pronouncedly, the obese PCOS patients $(26-30)$. This together with the increased androgen levels leads to a suppression of sex hormone-binding globulin (SHBG) in serum $(31,32)$. PCOS patients have also been reported to have increased urinary free $\mathrm{F}$ or $\mathrm{F}$ metabolite levels $(14,15,33)$.

As the value of the diagnostic test presented by Barnes $e t$ al. (6) has yet to be evaluated, the question arises of whether additional urinary steroid metabolite determinations during the course of the stimulation would be helpful to increase the diagnostic efficiency of the test. Regarding the high resolution gas chromatography analyses of unstimulated steroid concentrations in urine of PCOS patients reported by Rodin et al. (15), it would seem worthwhile to apply this technique in patients stimulated with the nafarelin test protocol. The aim of our study, therefore, is to evaluate the nafarelin test as a diagnostic tool for PCOS by measuring a subset of stimulated steroid metabolites in both the serum and urine of affected patients. In contrast to the original protocol using $100 \mu \mathrm{g} \mathrm{sc}$ administered nafarelin (6), an intranasal application of $1.20 \mathrm{mg}$ nafarelin was chosen. Additionally, we investigated the metabolic changes in serum and urinary steroids involved in adrenal and gonadal steroidogenesis. Besides the well known alterations in serum hormone levels, we document here significant changes in urinary steroid levels, especially with regard to androgens, gestagens, and corticoids, unmasked by the ovarian stimulation test.

\section{Subjects and Methods}

\section{Subjects}

Nineteen women with PCOS and 15 healthy women with regular menses every $26-32$ days were recruited for this study. All subjects were assumed to be free of acute or chronic disease based on a medical examination and clinical chemistry. Informed consent was obtained from all subjects. The study was approved by the ethical committees of the Ludwig-Maximilians University and the Technical University of Munich. Women with PCOS were patients admilted to the gynecological departments of the university hospitals of Grosshadern and Rechts der Isar; the clinical data of all subjects are given in Table 1.

The patients were diagnosed as having PCOS on the basis of the typical ultrasound features combined with two or more of the following clinical and biochemical criteria: 1) hirsutism (Ferriman-Gallwey score, $>6$ ), 2) infertility (duration of 2 yr minimum, after exclusion of other causes), 3) oligo/amenorrhea, and 4) free androgen index (FAI,T/SHBG $\times 100$ ) greater than 7 . Typical sonographic features included multiple cysts $(0.5-0.8 \mathrm{~cm}$ in diameter), arranged either peripherally or scattered throughout the ovarian stroma of the facultatively enlarged ovaries (34). Pelvic ultrasound examinations were performed with a 5-megahertz 240-degree phased array vaginal endoprobe (Combison 310, Kretz, Zipf Austria) by two investigators (T.S. and C.H.). Exclusion criteria for both the PCOS patients and the controls were 1) thyroid dysfunction, 2) hyperprolactinemia (PRL, $>570 \mathrm{mIU} / \mathrm{L}$; third international standard $84 / 500)$, 3) late-onset congenital adrenal hyperplasia (17HPROG in-

TABLE 1. Clinical characteristics of PCOS patients and controls

\begin{tabular}{lcr}
\hline & PCOS patients & Controls \\
\hline $\mathrm{n}$ & 19 & 15 \\
Age (a) & $28.1 \pm 1.1$ & $29.5 \pm 1.5$ \\
BMI & $26.4 \pm 1.5$ & $21.1 \pm 0.4$ \\
Hirsutism grading & $7.5 \pm 1.1$ & $2.0 \pm 0.4$ \\
$\quad$ (Ferriman-Gallwey) & & \\
Menstrual pattern & & \\
$\quad$ Regular & 3 & 15 \\
$\quad$ Oligomenorrhea & 5 & \\
$\quad$ Amenorrhea & 11 & \\
\hline
\end{tabular}


crease, $>45 \mathrm{nmol} / \mathrm{L}$ after adrenocortical stimulation with $0.25 \mathrm{mg}$ $\mathrm{ACTH}$, 4) endocrine-active tumors, 5) hormonal replacement therapy or oral contraceptives within the last 3 months, and 6) controls were excluded it they had polycystic ovaries on uitrasound.

\section{Nafarelin test}

The nafarelin test was performed in a modification of the original protocol (6); GnRHa was administered intranasally instead of sc (37). To each study subject, six sniffs (three sniffs in each nostril) of $0.23 \mathrm{mg}$ nafarelin acetate (Synarela, Syntex Pharma, Aachen, Germany), equivalent to a total of $1.20 \mathrm{mg}$ nafarelin, were administrated. The bioavailability of intranasally applied nafarelin is $3 \%(17,18)$, and the serum half-life is $4.4 \mathrm{~h}$. All subjerts were admitted to the ward on the morning of the test between $0800-1000 \mathrm{~h}$ between the third to sixth day of the menstrual cycle, if present. All subjects collected a pretest $24-\mathrm{h}$ urine sample. Blood samples were drawn $15 \mathrm{~min}$ before and $0,2,4$ and $24 \mathrm{~h}$ after nafarelin administration, and a second 24-h urine sample was collected with the time set from time zero. All blood and urine specimens were centrifuged at $2000 \times g$ and frozen at $-20 \mathrm{C}$ until analyzed. No serious side-effects were observed during our study.

\section{Hormonal analysis in serum}

Steroid measurements were performed in duplicate, using the following assays [in parentheses are indicated the manufacturer, interassay coefficient of variation (CV), mean, and lower detection limit (DL)]: $\mathrm{T}$, RIA [Immuchem, Carson, CA; CV, 9.7\%; mean, $25.3 \mathrm{nmol} / \mathrm{L}(\mathrm{n}=34)$; DL, $0.52 \mathrm{nmol} / \mathrm{L}$; A, RIA [Diagnostic Systems Laboratories, Webster, TX; CV, $18.6 \%(\mathrm{n}=10)$; mean, $5.6 \mathrm{nmol} / \mathrm{L}(\mathrm{n}=10) ; \mathrm{CV}, 9.0 \%$; mean, $30.1 \mathrm{nmol} / \mathrm{L}(\mathrm{n}=10) ; \mathrm{DL}, 0.18 \mathrm{nmol} / \mathrm{L}] ; \mathrm{E}_{2}$, enzyme immunoassay [Boehringer Mannheim, Mannheim, Germany; CV, 12.1\%; mean, 118 $\mathrm{pmol} / \mathrm{L}(\mathrm{n}=6) ; \mathrm{CV}, 9.9 \%$; mean, $2364 \mathrm{pmol} / \mathrm{L}(\mathrm{n}=6) ; \mathrm{DL}, 20 \mathrm{pmol} / \mathrm{L}]$; DHEAS, RIA [Diagnostic Products Corp., Los Angeles, CA; CV, 10.2\%; mean, $4.9 \mu \mathrm{mol} / \mathrm{L}(\mathrm{n}=13) ; \mathrm{CV}, 5.0 \%$; mean, $15.9 \mu \mathrm{mol} / \mathrm{L}(\mathrm{n}=13) ; \mathrm{DL}$, $0.13 \mu \mathrm{mol} / \mathrm{L}$ ]; 17HPROG, RIA [Diagnostic Products; CV, 16.3\%; mean, $12.1 \mathrm{nmol} / \mathrm{L}(\mathrm{n}=13) ; \mathrm{DL}, 0.30 \mathrm{nmol} / \mathrm{Ll}$; SHBG, immunoradiometric assay [Farmos Group, Oulunsalo, Finland; CV, $6.8 \%$; mean, $40 \mathrm{nmol} / \mathrm{L}$ $(\mathrm{n}=9)$; DL, $2.5 \mathrm{nmol} / \mathrm{Ll}$; LH, chemiluminescence immunoassay ICLIA; Kodak Clinical Diagnostics, Amersham, United Kingdom; CV, 4.0\%; mean, $18.8 \mathrm{mIU} / \mathrm{mL}(\mathrm{n}=12)$; DL, $0.5 \mathrm{mIU} / \mathrm{mLl}$; FSH, CLIA 「Kodak; CV, $2.6 \%$; mean, $9.0 \mathrm{mIU} / \mathrm{mL}(\mathrm{n}=12) ; \mathrm{DL}, 0.9 \mathrm{mIU} / \mathrm{mL}]$; androstanediol glucuronide (ADG), RIA [Diagnostic Systems Laboratories; CV, 5.6\%; mean, $16.6 \mathrm{nmol} / \mathrm{L}(\mathrm{n}=10) ; \mathrm{DL}, 0.6 \mathrm{nmol} / \mathrm{Ll} ; \mathrm{F}$ (in serum), CLIA [Kodak; CV, 3.8\%; mean, $574 \mathrm{nmol} / \mathrm{L}(\mathrm{n}=8) ; \mathrm{DL}, 13 \mathrm{nmol} / \mathrm{L}$ ]; F (free in urine), fluorescence polarization immunoassay without sample extraction [Abbott Laboratories, Irving, TX; CV, 6.1\%; mean, 397 nmol/L ( $\mathrm{n}=26$ ); DL, $25 \mathrm{nmol} / \mathrm{L}$; the cross-reactivity of the specific anti- $\mathrm{F}$ antibody to $\mathrm{E}$ is $1.1 \%$ ]; and progesterone (PROG), CLIA [Kodak; CV, $5.3 \%$; mean, $6.0 \mathrm{nmol} / \mathrm{L}(\mathrm{n}=12) ; \mathrm{DL}, 0.5 \mathrm{nmol} / \mathrm{L}]$. ADT glucuronide (ADTG) was determined according to the method previously described (35).

\section{Steroid analysis in urine}

Apparatus. For capillary gas chromatographic (GC) analyses, a model 3700 GC (Varian, Darmstadt, Germany) was used. Separations were obtained on a 30-m DB-1 fused-silica capillary column (internal diameter, $0.32 \mathrm{~mm}$; J \& W Scientific, Folsom, CA). The carrier gas was helium at a flow rate of $2.2 \mathrm{~mL} / \mathrm{min}$. The injector temperature was set at $290 \mathrm{C}$; the column temperature isothermal was $150 \mathrm{C}$ for $5 \mathrm{~min}$, then $150-300$ $C$ with a heating rate of $2 \mathrm{C} / \mathrm{min}$; the flame ionization detector temperature was $320 \mathrm{C}$; the splitting ratio was 1:20. A Mega-Integrator D-2500 (Merck, Darmstadt, Germany) was used as system controller. The reagents $\beta$-glucuronidase and arylsulfatase (type $\mathrm{H}-2$, crude solution from Helix pomatia), as well as the reference steroid compounds, and the hydrocarbon calibrators $\mathrm{C}_{22}$ (n-docosane), $\mathrm{C}_{24}$ (n-tetracosane), and $\mathrm{C}_{.32}$ (n-dotriacontane) were obtained from Sigma (Deisenhofen, Germany). N-Methyl- $N$-trimethylsilyl-trifluoroacetamide (MSTFA) was obtained from Fluka (Buchs, Switzerland), and cortolone (CORT) from Makor (Jerusalem, Israel). All other laboratory chemicals were purchased from Merck. Sep-Pak cartridges with $\mathrm{C}_{18}$ and $\mathrm{NH}_{2}$ materials were obtained from Millipore-Waters (Eschborn, Germany). For sample preparation, $1 / 100$ th of the $24-\mathrm{h}$ urine was used for analysis. After the

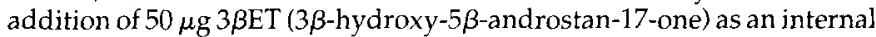
standard, the $\mathrm{pH}$ was adjusted to 4.6 with $3 \mathrm{~mol} / \mathrm{L}$ boric acid-acetate buffer. The mixture was adsorbed on a Sep-Pak $\mathrm{C}_{18}$ cartridge (38), which was primed twice with $5 \mathrm{~mL}$ methanol and twice with $5 \mathrm{~mL}$ water. The cartridge was eluted twice with $1-\mathrm{mL}$ portions of methanol, the eluate was evaporated at $50 \mathrm{C}$ under vacuum, and the residue was dissolved in $100 \mu \mathrm{L}$ methanol, $10 \mathrm{~mL}$ water, $1 \mathrm{~mL} 0.2 \mathrm{~mol} / \mathrm{L}$ sodium acetate buffer (pH 5.2), and $100 \mu \mathrm{L} \beta$-glucuronidase/arylsulfatase solution $(100,000$ $\mathrm{U} / \mathrm{mL}$ glucuronidase and $5,000 \mathrm{U} / \mathrm{mL}$ sulfatase; $\mathrm{U}=$ modified Fishman unit). I Iydrolysis was then performed at $55 \mathrm{C}$ for $2 \mathrm{~h}$ (39). The hydrolyzed residue was adsorbed again on a Sep-Pak $\mathrm{C}_{18}$ cartridge. One gram of anhydrous sodium sulfate was placed on the top of a $\mathrm{NH}_{2}$ cartridge, and the $\mathrm{C}_{18}$ cartridge was connected on the top of this (40). The cartridges were eluted with two portions of $1.5 \mathrm{~mL}$ ethyl acetate-methanol $(9: 1$, $\mathrm{vol} / \mathrm{vol}$ ). Twenty micrograms each of $\mathrm{C}_{22}, \mathrm{C}_{74}$, and $\mathrm{C}_{37}$ hydrocarbons dissolved in $100 \mu \mathrm{L} n$-hexane were added as calibrators for the retention indices to the eluate, and the solvents were then evaporated. The derivatization was performed with $50 \mu \mathrm{L}$ MSTFA and $100 \mu \mathrm{L}$ pyridine containing $10 \mathrm{mg}$ sodium acetate at $70 \mathrm{C}$ for $24 \mathrm{~h} \mathrm{(41).} \mathrm{Two} \mathrm{microliters}$ were used for GC analysis. This procedure of derivatization fully converts 17-keto groups into enol-trimethylsilyl ethers and hydroxy groups into trimethylsilyl derivatives, with the exception of 11-hydroxy and 11-keto groups.

Peak identification: By coinjection of authentic steroid compounds (extracted in parallel with the urine samples), the methylene units of the relevant steroids were calculated and used to identify the peaks. Confirmation of steroid identity, when necessary, was assessed by GC/mass spectrometry techniques.

Peak quantification: The steroid concentrations found in urine were calculated from peak area ratios related to the internal standard $3 \beta E T$ and expressed as micromoles of steroid per $g$ creatinine in the respective urines.

A typical urinary steroid profile of a PCOS patient performed using the GC technique applied is shown in Fig. 1. The overall interassay CV for all steroids measured was $4.5 \%(n=6)$.

\section{Statistical analysis}

Statistical analyses were calculated using the BMDP386 package (version 7.0, BMDP Statistical Software, Los Angeles, CA). Initial plots of several steroid parameters showed skewed distributions, precluding the assumption of normal data distributions, and therefore, we used a nonparametric test panel in an exploratory evaluation. Hormone variables between the groups were compared by use of the Mann-Whitney rank sum test; the intragroup changes during the test were compared by use of either the Wilcoxon test (applied for urinary analytes) or the Friedman test (applied for serum analytes). Optimal cut-off values for the distinction of the steroid analytes 17HPROG, 17\%-hydroxypregnanolone

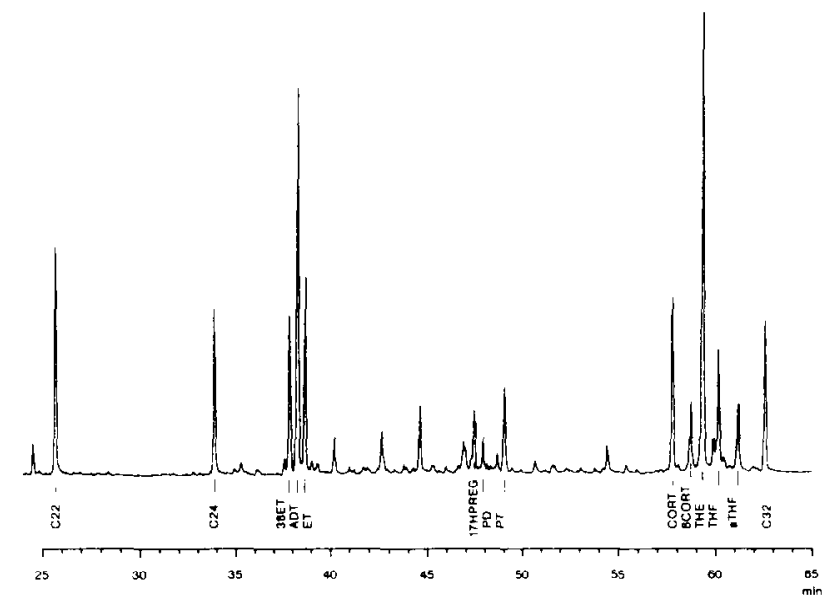

FIG. 1. Typical urinary sternid profile from a PCOS patient, performed by use of the GC technique. 
(17HPREG), and allo-tetrahydrocortisol (aTHF) between PCOS patients and controls were derived from receiver-operating characteristic plots. All results are presented as the mean \pm SEM.

\section{Results}

\section{Serum levels of gonadotropins and steroids}

The intranasal application of nafarelin resulted in a significant rise in serum LH and FSH levels $(P<0.001)$ in all women (PCOS patients and controls). For both gonadotropins, peak levels occurred after $4 \mathrm{~h}$. Two patients showed increasing concentrations of LH or FSH even up to the last measurement at $24 \mathrm{~h}$. In all women tested with nafarelin, the levels of $\mathrm{LH}$ and $\mathrm{FSH}$ at $24 \mathrm{~h}$ were higher than the respective basal pretest values. As shown in Table 2, there were no significant differences between controls and PCOS patients in basal or stimulated LH or FSH levels. The LH/FSH ratio, however, was significantly higher in PCOS patients than in controls $24 \mathrm{~h}$ after GnRHa application $(2.6 \pm 0.4$ vs. $1.6 \pm 0.1 ; P<0.05)$.

Serum 17HPROG levels were elevated at all time points in PCOS patients compared with those in control subjects $(P<$ 0.001 ). The baseline level of 17HPROG in PCOS patients was $3.5 \pm 0.2$ compared to $1.8 \pm 0.1 \mathrm{nmol} / \mathrm{L}$ in the controls. In both groups, 17HPROG and its precursor, PROG, rose significantly during the test $(P<0.001$; Table 2 and Fig. 2$)$; the rates of increase in 17HPROG were similar in the two groups. At baseline, no difference was seen in the serum levels of PROG between the groups.

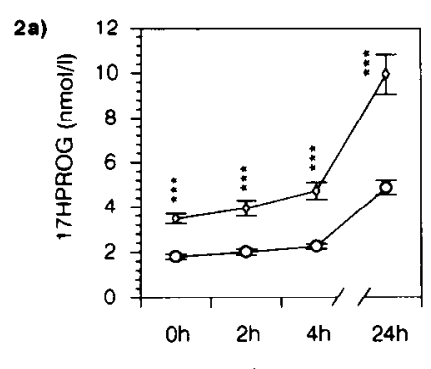

2b)

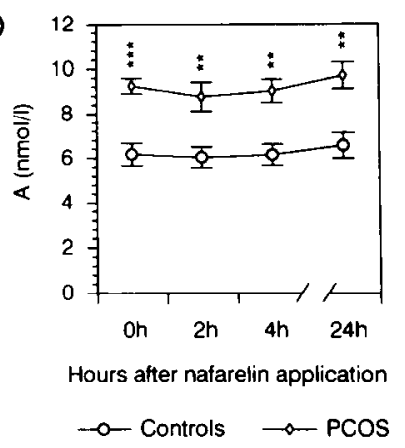

FIG. 2. Responses of 17HPROG (a) and A (b) to nafarelin in sera of PCOS patients and controls. Serum concentrations are given as the mean \pm SEM. Significant differences between PCOS and controls are indicated: **, $P<0.01$; ***, $P<0.001$.

Basal serum A levels were higher in PCOS patients than in controls $(9.2 \pm 0.3$ vs. $6.2 \pm 0.5 \mathrm{nmol} / \mathrm{L} ; P<0.001)$. Neither the PCOS patients nor the controls exhibited a significant change in A levels during the test (Table 2). Similar to those of $A$, the basal serum levels of $T$ were elevated in PCOS patients compared to the control values $(2.2 \pm 0.2$ vs. $1.5 \pm$ $0.1 \mathrm{nmol} / \mathrm{L} ; P<0.05)$. Only in the PCOS patients was a significant rise in $\mathrm{T}$ observed during the test (at $24 \mathrm{~h}, 3.2 \pm$ 0.4 vs. $1.8 \pm 0.2 \mathrm{nmol} / \mathrm{L} ; P<0.01$ ). SHBG levels were lower in the PCOS patients than in the controls (data not shown). Therefore, the FAI levels were significantly higher in the PCOS patients, both basally and during the course of the

TABLE 2. Mean values and ranges ( \pm SEM) for serum parameters in the course of the nafarelin test for PCOS patients and controls after intranasal nafarelin application

\begin{tabular}{|c|c|c|c|c|c|}
\hline Group & Parameter & Basal $0 \mathrm{~h}$ & Post $2 \mathrm{~h}$ & Post $4 \mathrm{~h}$ & Post $24 \mathrm{~h}$ \\
\hline Controls & $\begin{array}{l}\text { LH }(\text { IU/L) } \\
\text { FSH }(\text { IU/L) } \\
\text { LH/FSH ratio } \\
\text { A (nmol/L) } \\
\text { T (nmol/L) } \\
\text { FAI }(\%) \\
\text { DHEAS }(\mu \mathrm{mol} / \mathrm{L}) \\
\text { PROG }(\mathrm{nmol} / \mathrm{L}) \\
17 \mathrm{HPROG}(\mathrm{nmol} / \mathrm{L}) \\
\text { ADG }(\mathrm{nmol} / \mathrm{L}) \\
\text { ADTG }(\mathrm{nmol} / \mathrm{L}) \\
E_{2}(\mathrm{pmol} / \mathrm{L}) \\
\text { F }(\mathrm{nmol} / \mathrm{L})\end{array}$ & $\begin{array}{l}4.1 \pm 0.5 \\
5.5 \pm 0.5 \\
0.8 \pm 0.1 \\
6.2 \pm 0.5 \\
1.5 \pm 0.1 \\
3.0 \pm 0.4 \\
6.1 \pm 0.5 \\
1.6 \pm 0.2 \\
1.8 \pm 0.1 \\
9.0 \pm 1.2 \\
162 \pm 26.9 \\
111 \pm 18 \\
257 \pm 27\end{array}$ & $\begin{array}{r}35.5 \pm 4.1 \\
13.9 \pm 1.1 \\
2.6 \pm 0.3 \\
6.0 \pm 0.5 \\
1.4 \pm 0.1 \\
2.7 \pm 0.3 \\
6.2 \pm 0.6 \\
1.6 \pm 0.2 \\
2.0 \pm 0.1 \\
9.0 \pm 1.1 \\
\\
209 \pm 23\end{array}$ & $\begin{array}{r}62.2 \pm 6.5 \\
23.5 \pm 2.0 \\
2.7 \pm 0.3 \\
6.1 \pm 0.5 \\
1.4 \pm 0.1 \\
2.7 \pm 0.3 \\
6.3 \pm 0.6 \\
1.7 \pm 0.2 \\
2.2 \pm 0.1 \\
9.4 \pm 1.1 \\
\end{array}$ & $\begin{array}{c}22.1 \pm 2.6^{a} \\
13.7 \pm 1.4^{a} \\
1.6 \pm 0.1^{a} \\
6.6 \pm 0.6 \\
1.8 \pm 0.2 \\
3.6 \pm 0.5^{b} \\
6.1 \pm 0.5 \\
2.8 \pm 0.5^{a} \\
4.9 \pm 0.3^{a} \\
9.5 \pm 1.2 \\
166 \pm 30.3 \\
591 \pm 67^{a} \\
218 \pm 17\end{array}$ \\
\hline PCOS patients & $\begin{array}{l}\text { LH (IU/L) } \\
\text { FSH }(\text { IU/L) } \\
\text { LH/FSH ratio } \\
\text { A }(\mathrm{nmol} / \mathrm{L}) \\
\text { T }(\mathrm{nmol} / \mathrm{L}) \\
\text { FAI }(\%) \\
\text { DHEAS }(\mu \mathrm{mol} / \mathrm{L}) \\
\text { PROG }(\mathrm{nmol} / \mathrm{L}) \\
17 \mathrm{HPROG}(\mathrm{nmol} / \mathrm{L}) \\
\text { ADG }(\mathrm{nmol} / \mathrm{L}) \\
\text { ADTG }(\mathrm{nmol} / \mathrm{L}) \\
\mathrm{E}_{2}(\mathrm{pmol} / \mathrm{L}) \\
\text { F }(\mathrm{nmol} / \mathrm{L})\end{array}$ & $\begin{array}{c}5.6 \pm 0.8 \\
6.0 \pm 0.4 \\
1.0 \pm 0.1 \\
9.2 \pm 0.3^{d} \\
2.2 \pm 0.2^{c} \\
12.8 \pm 3.6^{e} \\
6.3 \pm 0.7 \\
1.7 \pm 0.3 \\
3.5 \pm 0.2^{d} \\
8.9 \pm 1.5 \\
216 \pm 25.6 \\
132 \pm 11 \\
378 \pm 27^{e}\end{array}$ & $\begin{aligned} 37.7 & \pm 4.2 \\
13.3 & \pm 1.1 \\
3.0 & \pm 0.3 \\
8.8 & \pm 0.6^{e} \\
2.2 & \pm 0.2^{c} \\
12.5 & \pm 3.8^{e} \\
6.4 & \pm 0.7 \\
1.8 & \pm 0.4 \\
3.9 & \pm 0.3^{d} \\
8.5 & \pm 1.4 \\
& \\
283 & \pm 21^{c}\end{aligned}$ & $\begin{aligned} & 62.2 \pm 7.2 \\
& 20.5 \pm 1.6 \\
& 3.3 \pm 0.4 \\
& 9.0 \pm 0.5^{e} \\
& 2.1 \pm 0.2^{c} \\
& 13.8 \pm 4.5^{e} \\
& 6.6 \pm 0.7 \\
& 2.3 \pm 0.5 \\
& 4.7 \pm 0.4^{d} \\
& 8.4 \pm 1.4\end{aligned}$ & $\begin{aligned} 33.0 & \pm 6.5^{a} \\
12.3 & \pm 1.2^{a} \\
2.6 & \pm 0.4^{a, c} \\
9.7 & \pm 0.6^{e} \\
3.2 & \pm 0.4^{c, f} \\
18.1 & \pm 5.5^{e, f} \\
6.4 & \pm 0.8 \\
3.4 & \pm 0.8^{a} \\
9.9 & \pm 0.9^{a, d} \\
9.8 & \pm 1.6^{b} \\
231 & \pm 27.2 \\
950 & \pm 123^{a, r} \\
360 & \pm 38^{e}\end{aligned}$ \\
\hline
\end{tabular}

${ }^{a} P<0.001$, significant changes in the course of the nafarelin test (Friedman test).

${ }^{b} P<0.05$, significant changes in the course of the nafarelin test (Friedman test).

${ }^{c} P<0.05$, PCOS vs. controls (Mann-Whitney test).

${ }^{d} P<0.001$, PCOS us. controls (Mann-Whitney test).

${ }^{e} P<0.01$, PCOS vs. controls (Mann-Whitney test).

${ }^{f} P<0.01$, significant changes in the course of the nafarelin test (Friedman test). 
test lat baseline, $12.8 \pm 3.6 \%$ vs. $3.0 \pm 0.4 \%(P<0.01)$; at $24 \mathrm{~h}, 18.1 \pm 5.5 \%$ vs. $3.6 \pm 0.5 \%(P<0.01)]$. $\mathrm{E}_{2}$ levels rose significantly $(P<0.001)$ in both groups during the test; the posttest levels were significantly higher in PCOS than in controls $(950 \pm 123$ vs. $591 \pm 67 \mathrm{pmol} / \mathrm{L} ; P<0.05)$.

Neither serum DIIEAS, ADG, nor ADTG concentrations showed any significant differences when comparing PCOS and controls. Although ADG levels increased as a result of nafarelin stimulation $(P<0.05)$, no changes in the serum concentrations of ADTG or DHEAS were observed (Table 2).

Serum $F$ levels were higher in PCOS patients than controls at all time points $(P<0.01$ at 0 and $24 \mathrm{~h} ; P<0.05$ at 2 and $4 \mathrm{~h}$ ). Due to the dynamic fluctuations in serum F during the day, the Friedman test was not applied to the different values of the two groups.

\section{Levels of steroids in the 24-h urine samples}

The results of the steroid profiles for both the PCOS patients and the controls during the nafarelin test are shown in Table 3. In the controls, only 17HPREG levels were signifi- cantly stimulated $(P<0.05)$ by nafarelin; all other steroid levels remained unchanged. In PCOS patients, however, there were significant increases in urinary androgen derivatives (ADT and ET), gestagens [17HPREG and pregnanetriol (PT)] and glucocorticoids [tetrahydrocortisone (THE), THF, CORT, and $\beta$-cortolone ( $\beta$ CORT)] including free $F$ (see Table 3 for significances). With respect to the differences observed between the patients and controls, the following parameters were higher at baseline: THE ( $P$ $<0.05)$, aTHF $(P<0.5)$, ADT $/$ ET ratio $(P<0.05)$, and aTHF/THF ratio $(P<0.01)$. Ratios of ADT / ET and aTHF/ THF may be considered to be indirect measures of $5 \alpha-$ reductase activity. After stimulation, the following parameters were higher in PCOS patients: ADT $(P<0.01)$, 17HPREG $(P<0.05)$, PT $(P<0.05)$, THE $(P<0.05)$, THF $(P<0.05)$, aTHF $(P<0.001)$, ADT $/$ ET ratio $(P<0.05)$, corticoid sum ( = CORT + $\beta$ CORT + THE + THF + aTHF $)$ $(P<0.05)$, and free $\mathrm{F}(P<0.05)$. Significant stronger increases over $24 \mathrm{~h}$ were found in urine from PCOS patients for ADT, ET, 17HPREG, PT, CORT, THF, and free F

TABLE 3. Mean values and ranges $( \pm$ SEM) for urine parameters pre- and postnafarelin testing for PCOS patients and controls

\begin{tabular}{|c|c|c|c|c|}
\hline Group & Parameter & Pretest & Posttest & Difference \\
\hline Controls & $\begin{array}{l}\text { ADT } \\
\text { ET } \\
\text { DHEA } \\
\text { 17HPREG } \\
\text { PD } \\
\text { PT } \\
\text { THS } \\
\text { CORT } \\
\beta C O R T \\
\text { THE } \\
\text { TIIF } \\
\text { aTHF } \\
\text { ADT/ET ratio } \\
\text { THE/THF ratio } \\
\text { aTHF/THF ratio } \\
\text { Cort.-sum } \\
\text { F }\end{array}$ & $\begin{aligned} & 7.4 \pm 0.8 \\
& 11.5 \pm 1.3 \\
& 2.9 \pm 0.8 \\
& 1.3 \pm 0.3 \\
& 10.4 \pm 2.2 \\
& 3.5 \pm 0.3 \\
& 0.8 \pm 0.1 \\
& 4.1 \pm 0.3 \\
& 2.9 \pm 0.2 \\
& 9.5 \pm 0.7 \\
& 5.3 \pm 0.5 \\
& 1.8 \pm 0.1 \\
& 0.7 \pm 0.1 \\
& 1.91 \pm 0.14 \\
& 0.37 \pm 0.04 \\
& 23.6 \pm 1.6 \\
& 256 \pm 19\end{aligned}$ & $\begin{aligned} & 7.2 \pm 0.8 \\
& 11.3 \pm 1.2 \\
& 2.2 \pm 0.4 \\
& 1.6 \pm 0.3 \\
& 9.4 \pm 2.0 \\
& 3.6 \pm 0.3 \\
& 0.7 \pm 0.1 \\
& 3.9 \pm 0.3 \\
& 2.7 \pm 0.2 \\
& 9.9 \pm 0.8 \\
& 5.4 \pm 0.4 \\
& 1.8 \pm 0.1 \\
& 0.7 \pm 0.1 \\
& 1.86 \pm 0.09 \\
& 0.34 \pm 0.02 \\
& 23.7 \pm 1.6 \\
& 261 \pm 17\end{aligned}$ & $\begin{aligned} &-0.2 \pm 0.3 \\
&-0.2 \pm 0.6 \\
&-0.8 \pm 0.7 \\
& 0.3 \pm 0.1^{a} \\
&-1.0 \pm 1.0 \\
& 0.1 \pm 0.2 \\
&-0.2 \pm 0.1 \\
&-0.2 \pm 0.3 \\
&-0.2 \pm 0.2 \\
& 0.4 \pm 0.4 \\
& 0.1 \pm 0.4 \\
& 0.0 \pm 0.1 \\
&-0.05 \pm 0.14 \\
&-0.03 \pm 0.04 \\
& 0.1 \pm 1.1 \\
& 5 \pm 19\end{aligned}$ \\
\hline PCOS patients & $\begin{array}{l}\text { ADT } \\
\text { ET } \\
\text { DHEA } \\
\text { 17HPREG } \\
\text { PD } \\
\text { PT } \\
\text { TIIS } \\
\text { CORT } \\
\beta C O R T \\
\text { THE } \\
\text { THF } \\
\text { aTHF } \\
\text { ADT/ET ratio } \\
\text { THE/THF ratio } \\
\text { aTHF/THF ratio } \\
\text { Cort.-sum } \\
\text { F }\end{array}$ & $\begin{aligned} & 10.0 \pm 0.9 \\
& 10.7 \pm 0.7 \\
& 3.9 \pm 1.3 \\
& 1.3 \pm 0.2 \\
& 6.4 \pm 1.2 \\
& 4.1 \pm 0.4 \\
& 0.6 \pm 0.1 \\
& 4.5 \pm 0.6 \\
& 2.5 \pm 0.3 \\
& 12.1 \pm 0.9^{d} \\
& 5.7 \pm 0.5 \\
& 2.8 \pm 0.3^{d} \\
& 1.0 \pm 0.1^{d} \\
& 2.23 \pm 0.12^{d} \\
& 0.52 \pm 0.05^{b} \\
& 27.6 \pm 2.1 \\
& 279 \pm 19\end{aligned}$ & $\begin{array}{c}13.4 \pm 1.5^{b} \\
14.9 \pm 1.8 \\
3.5 \pm 1.0 \\
2.6 \pm 0.3^{d} \\
8.2 \pm 1.5 \\
6.1 \pm 0.7^{d} \\
0.8 \pm 0.1 \\
5.6 \pm 0.8 \\
3.6 \pm 0.5 \\
16.4 \pm 2.1^{d} \\
8.1 \pm 0.9^{d} \\
3.4 \pm 0.4^{e} \\
1.0 \pm 0.1^{d} \\
2.03 \pm 0.10 \\
0.45 \pm 0.05 \\
37.2 \pm 4.3^{d} \\
350 \pm 25^{d}\end{array}$ & $\begin{array}{c}3.3 \pm 1.0^{b, c} \\
4.3 \pm 1.5^{c, d} \\
0.1 \pm 0.9 \\
1.4 \pm 0.2^{e, f} \\
1.7 \pm 1.3 \\
1.9 \pm 0.5^{b, f} \\
0.3 \pm 0.2 \\
1.1 \pm 0.5^{a, d} \\
1.1 \pm 0.4^{a} \\
4.2 \pm 1.8^{a} \\
2.4 \pm 0.9^{c, d} \\
0.6 \pm 0.3 \\
\\
-0.24 \pm 0.10^{a} \\
-0.08 \pm 0.03^{c, d} \\
9.4 \pm 3.7^{a} \\
72 \pm 25^{a, d}\end{array}$ \\
\hline
\end{tabular}

All parameters, except ratios and $F$, are given as micromoles per $g$ creatinine; $F$ is given as nanomoles per $g$ creatinine. Cort.-sum, CORT $+\beta$ CORT + THE + THF + aTHF

${ }^{a} P<0.05$, pre- vs. postnafarelin (Wilcoxon test).

${ }^{b} P<0.01$, PCOS vs. controls (Mann-Whitney test).

c $P<0.01$, pre- vs. postnafarelin (Wilcoxon test).

${ }^{d} P<0.05$, PCOS $v s$. controls (Mann-Whitney test).

${ }^{e} P<0.001$, PCOS $v s$. controls (Mann-Whitney test).

${ }^{f} \mathrm{P}<0.001$, pre- vs. postnafarelin (Wilcoxon test). 
compared to those in the healthy controls. The most prominent differences between the two groups were found for the increase in 17HPREG levels ( $1.4 \pm 0.2$ vs. $0.3 \pm 0.1$ $\mu \mathrm{mol} / \mathrm{g}$ creatinine; $P<0.001)$ and the poststimulation value of aTHF $(3.4 \pm 0.4$ vs. $1.8 \pm 0.1 \mu \mathrm{mol} / \mathrm{g}$ creatinine; $\mathrm{P}<0.001$ ), as shown in Fig. 3. Tetrahydro-11-deoxycortisol (THS), a derivative of the F precursor 11-deoxycortisol, was found only in low concentrations in both patients and controls, and significant differences or changes could not be determined. In contrast to PT (a derivative of 17HPROG), no significant differences or changes were seen in pregnanediol (PD) levels, which is a product of PROG.

The ratio of THE/THF, an indicator of the $11 \beta \mathrm{HSDH}$ activity and similar to the ratio of the 11-oxo/11-hydroxy metabolites of $\mathrm{F}$ was significantly different $(P<0.05)$ in PCOS patients vs. controls at baseline, whereas in the course of the test, the PCOS patients showed a significant decrease $(P<0.05)$.

Calculation of sensitivities and specificities of several analytes in the course of the test revealed that, based on $93 \%$ specificity, the posttest 17HPROG level in serum has a sensitivity of $89 \%$ (cut-off value, $6.4 \mathrm{nmol} / \mathrm{L}$ ), whereas in urine, the pusttest aTHF level shows a sensitivity of $78 \%$ (cut-off value, $2.26 \mu \mathrm{mol} / \mathrm{g}$ creatinine), and the difference value of 17HPREG shows a sensitivity of $72 \%$ (cut-off value 0.8 $\mu \mathrm{mol} / \mathrm{g}$ creatinine). The sum of both urinary parameters resulted in a sensitivity of $89 \%$ (cut-off value, $2.8 \mu \mathrm{mol} / \mathrm{g}$ creatinine).

Additionally, correlations between the urinary steroid metabolites were determined. In the patient group, there were significant positive correlations between the following posttest parameters: 17HPREG correlates with THE, THF, CORT, $\beta C O R T, A D T, E T$, and PT; and PT correlates with CORT, $\beta C O R T, T H E, T H F, E T$, and ADT. The respective $P$ values varied between less than 0.001 (17HPREG vs. PT or PT vs. ET) and 0.013 (17HPREG vs. CORT). No significant correlations were observed in the control group.
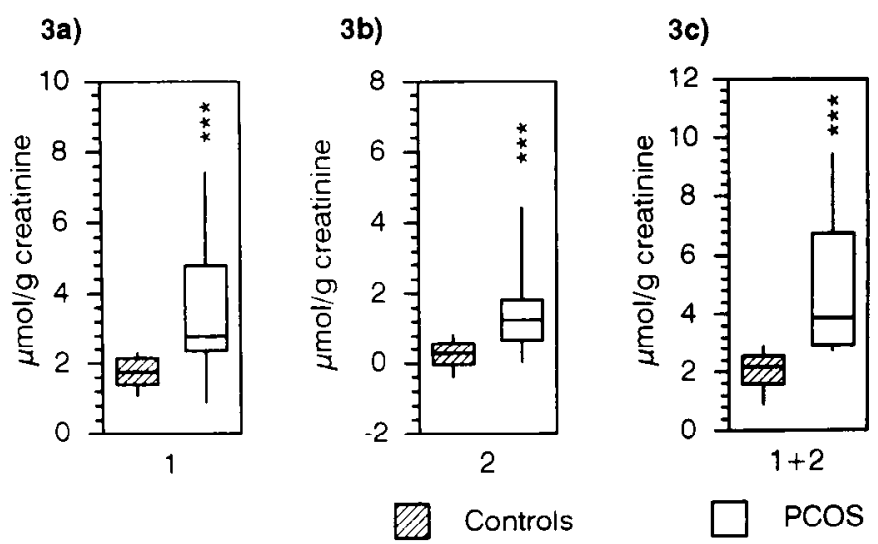

FIG. 3. Box and whisker plots (graphical displays of the data distributions) of the posttest levels of aTHF ( $a ; 1)$, the difference values of 17HPREG $(b ; 2)$, and the combination of both $(c ; 1+2)$ in urine of PCOS patients and controls undergoing nafarelin testing. The box and whisker plot presentation shows the median, $25-75 \%$ range, and extremes (without outliers). Significant differences between PCOS and controls are indicated: ${ }^{*}, P<0.05$; ${ }^{* *}, P<0.01$; ***, $P<0.001$.
The serum and urine test parameters described above were not significantly different in lean and obese PCOS subjects.

\section{Discussion}

The use of basal hormone levels, LH/FSH ratios, elevated androgen levels, or pelvic ultrasound examinations often fail to give reliable diagnostic indications for PCOS. The nafarelin test, developed by Barnes et al. (6), was the first test to assess suitable biochemical criteria for the diagnosis. The GnRHa nafarelin is a potent specific stimulator of the pituitary-gonadal axis; given as a single dose, it is much more potent than the commonly used GnRH. A short term stimulation test using this drug appears to be a useful tool in distinguishing PCOS from other causes of hyperandrogenism in women (7). Our study, using an intranasal application with pharmacodynamically equivalent doses, has confirmed these data concerning levels of 17HPROG and the gonadotropins in serum. In addition, we were able to document significant changes in urinary steroid metabolite levels, especially in those of androgens, gestagens, and corticoids.

In accordance with the data described by Barnes et al. (6), we found that the maximal gonadotropin responses in serum occurred after $4 \mathrm{~h}$, whereas the ovarian steroid responses continued to rise during the entire 24-h test period. The $\mathrm{LH} / \mathrm{FSH}$ ratio was clearly elevated in the patients at $24 \mathrm{~h}$, as expected for this disorder. The most distinctive increase was that found for 17HPROG. In contrast to the findings of Barnes et al. (6), we observed no significant change in $A$ in either the PCOS patients or controls, although the respective levels were higher in the patient group throughout. In contrast $T$ together with $\mathrm{A}$, a product of the $\mathrm{P} 450 \mathrm{c} 17 \alpha$ enzyme complex, was found to be elevated in the PCOS patients compared to control levels and underwent a significant increase during the test in the patients. Of the T metabolites ADG and ADTG, only ADG significantly increased during the test in the PCOS patients. The observation that the concentration of ADTG remained unchanged in PCOS patients together with a marginally elevated $T$ level can be explained by the fact that in our patient group the androgen excess was only moderate and the mean Ferriman-Gallwey index for the group of 19 patients was 7.5. Serum DHEAS, the main adrenal androgen parameter, showed no changes during the test in either group. The $\mathrm{E}_{2}$ response to nafarelin was exaggerated in PCOS patients compared to the controls.

These data give rise to the suggestion that cytochrome P $450 \mathrm{c} 17 \alpha$ may be dysregulated in the PCOS patients. Nevertheless, with regard to the serum $\mathrm{T}$ concentrations of the affected patients, increased activities of both the ovarian $17 \alpha$-hydroxylase and 17,20-lyase enzymes in the $\Delta^{4}$-steroid pathway cannot be ruled out. In addition to the diagnostic discrimination afforded by baseline parameters such as $17 \mathrm{HPROG}$ (with a sensitivity of $78 \%$ at $93 \%$ specificity; cutoff value, $2.5 \mathrm{nmol} / \mathrm{L}$ ), only the posttest serum levels of 17HPROG allow a further distinction to be drawn between PCOS patients and controls with a sensitivity of $89 \%$ at $93 \%$ specificity (cut-off value, $6.4 \mathrm{nmol} / \mathrm{L}$ ).

Applying the high resolution GC technique using the MSTFA derivatization method to the urine samples, we were 
able to quantify the abnormal steroidogenic response to nafarelin in the affected patients. The examination of the respective steroid profiles in the test subjects revealed a quite different pattern in the PCOS patients compared to the controls. In healthy women, only $17 \mathrm{HPREG}$, the urinary derivative of 17HPROG, showed an significant increase during the test. In patients, however, there was a significant increase in the urinary metabolites of androgens (ADT and ET), gestagens (17HPREG, PD, and PT), and glucocorticoids (THE, THF, aTHF, CORT, $\beta$ CORT, and F).

In our study, the urinary steroid profiles revealed greater $5 \alpha \mathrm{THF} / 5 \beta \mathrm{THF}$ and ADT/ET ratios in PCOS patients (Fig. 4). This is in accordance with the report of Stewart et al. (14), who demonstrated increased $5 \alpha$-reductase activity in the liver and
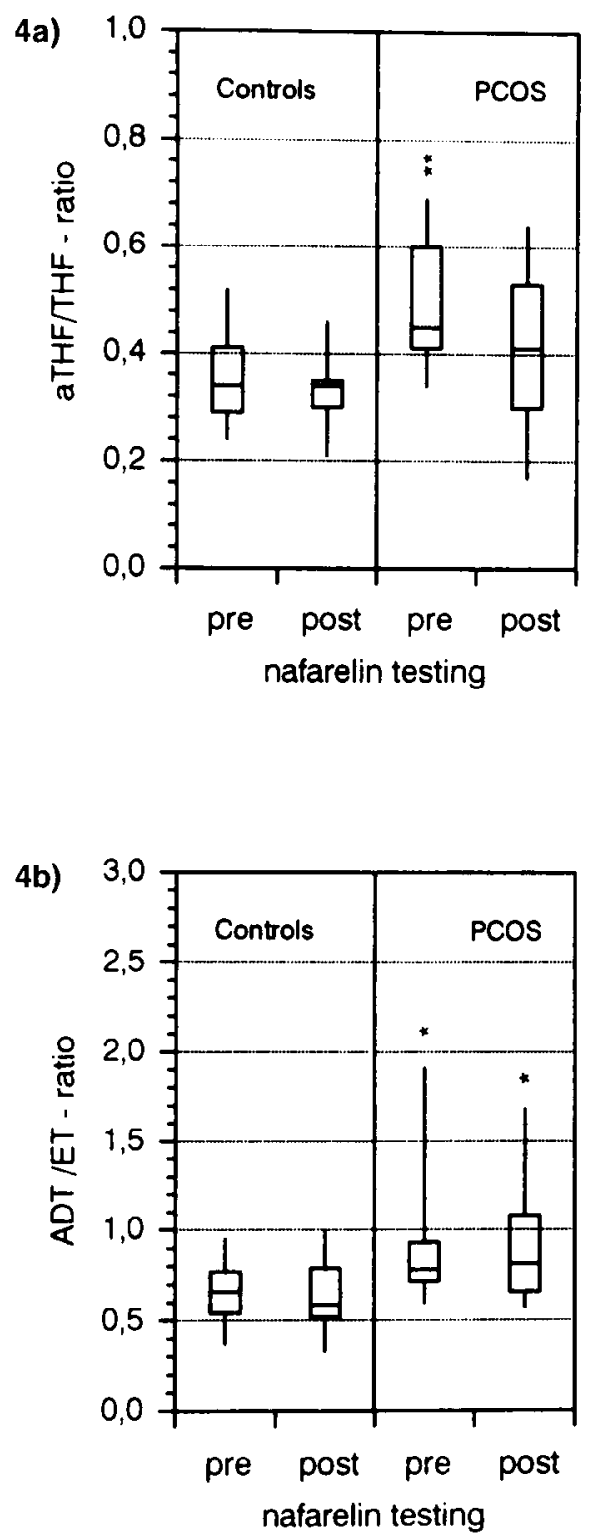

FIG. 4. Box and whisker plots of the $5 \alpha$-reductase ratios of aTHF/ THF (a) and ADT/ET (b) in urine of PCOS patients and controls before and after nafarelin testing. The box and whisker plot presentation shows the median, 25-75\% range, and extremes (without outliers). Significant differences between PCOS and controls are indicated: *, $P<0.05 ;^{* *}, P<0.01 ;{ }^{* * *}, P<0.001$. skin of patients suffering from this endocrinc disorder. In the course of the nafarelin test, however, only the aTHF/THFratio is altered, due to an increase in aTHF levels; the origin of this increased $5 \alpha$-reductase activity level in PCOS is still under debate. According to Rosenfield (42), the overproduction of ovarian androgens seems to result in a stimulation of this enzyme in skin and liver $(12,13)$. The borderline change in aTHF secretion in urine that was observed $(P=0.07)$ also suggests that the enhanced $5 \alpha$-reductase activity may be the result of androgen excess and not due to a primary mechanism, as reported by Stewart et al. (14).

According to Giagulli et al. (12), ADG appears to be a better parameter for determining peripheral $5 \alpha$-reductase activity than ADT. Therefore, it would be necessary to determine the levels of urinary androstanediol, rather than ADT, to confirm our model. This, however, was not possible with the GC technique applied in this study due to peak interferences.

It can be stated that the basal serum $F$ level and basal free $F$ level in urine are slightly elevated in PCOS patients compared with those in controls. This may be due to a preexisting alteration in adrenal corticoid secretion. Invitti et al. (33) documented an increased urinary free $F$ level in PCOS patients and suggested that an overactive hypothalamic-pituitary-adrenal axis might be responsible. Rodin et $u l$. (15) reported increased adrenal secretion of $\mathrm{F}$ due to an augmented adrenocortical activity in women with PCOS, but decreased urinary free $\mathrm{F}$ levels. The exaggerated glucocorticoid excretion in PCOS patients after naferelin treatment, however, is surprising and could be explained by an increased oxidation of $\mathrm{F}$ to $\mathrm{E}$ due to a dysregulated $11 \beta \mathrm{HSDH}$, which is not accounted for by obesity. As a result of the enhanced $F$ clearance rate, the synthesis of adrenal androgens is augmented. In our study, the THE/THF ratio was significantly higher in PCOS patients os. controls at baseline $(P<0.05)$, which is in agreement with the ratio of the 11-oxo/11-hydroxy metabolites of $F$ reported by Rodin et al. (15). In the course of the test, however, the PCOS patients showed a decrease in this ratio, which results in a loss of significance in the differences between the ratios in PCOS and control subjects. Therefore, it can be suggested that the abnormal $11 \beta \mathrm{HSDH}$ activity is attenuated in the course of the GnRHa test. Due to a reduced conversion of $F$ to $F$, the excretion of the respective $F$ and corticosterone metabolites increases acutely over the 24-h test period. Our hypothesis is that the excess production of $E_{2}$ released by the gonadotropin surge in PCOS patients $v s$. controls is able to attenuate the $11 \beta \mathrm{HSDH}$ activity. Together with an increased metabolism of 17HPROG toward PT, this would explain the increased corticoid excretion in urine and the absence of a parallel increase in $\mathrm{A}$ and $\mathrm{T}$ in relation to 17HPROG in serum during the GnRHa test. Another possible explanation for the enhanced glucocorticoid excretion in PCOS patients after nafarelin application is that the gestagen surge that results from GnRHa stimulation displaces serum F from corticosteroidbinding globulin and leads to an augmented F metabolism. It has previously been described that serum corticosteroidbinding globulin levels are significantly decreased in PCOS patients (33).

Therefore, our data suggest that an altered interconversion of $F$ and $E$ is able to play a role in PCOS, as suggested for the 
augmented/dysregulated ovarian cytochrome $\mathrm{P} 450 \mathrm{c} 17 \alpha$ activity. The proportion and importance of the proposed enzyme dysregulation in the pathogenesis of PCOS have yet to be proven, because measurements of basal serum levels of 11-hydroxyandrostenedione, a marker of adrenal androgen secretion, support the idea that the ovaries and not the adrenals are the major source of androgens in PCOS (5). Additionally, divergent results concerning the elevation of DHEAS levels in PCOS patients have previously been described $(22,23,43,44)$ and argue against a pivotal role of the adrenal glands in the etiology of this disorder. However, an altered sensitivity of the adrenal cortex to corticotropin, evidenced by higher 11-hydroxyandrostenedione levels after stimulation with corticotropin-releasing factor and an increased metabolic clearance of $\mathrm{F}$ and corticosterone, appears to be a supplementary symptom of the pathophysiological changes in PCOS.

One additional observation from our study is that, interestingly, in the PCOS patients, no significant differences in urinary steroid concentrations between the lean and obese patients could be found during the test. This would appear to rule out the idea that increased $F$ production rates in obesity cause higher secretion rates of $\mathrm{E}$ in the adipose tissue of PCOS patients.

This study, undertaken with 19 PCOS patient and 15 controls, documents the efficiency of the nafarelin test in confirming the ovarian abnormality in PCOS suspected by the clinical diagnosis. The more practical intranasal application mode together with the measurements of urinary steroids gives an effective diagnostic tool for investigating this endocrine disorder. The study suggests that 17HPROG levels in serum together with those of aTHF and 17HPREG in urine are the best discriminatory parameters of the GnRHa stimulation test. An additional investigation concerning these three parameters should confirm our results by the application of confirmatory statistical analysis.

The sensitivity of the test, as defined by the ability to detect an ovarian abnormality, was $89 \%$ for both the posttest level of 17HPROG in serum and the combination of the difference value of 17HPREG and the posttest value of aTHF in urine (all at a $93 \%$ specificity). Further studies are necessary to determine whether a combination of the nafarelin stimulation test with, for example, short term dexamethasone suppression, is capable of distinguishing between the different forms of hyperandrogenism in women.

Due to the variability of symptoms displayed by patients suffering from this endocrine disorder, additional investigation is required to confirm whether the suggested dysregulated enzyme systems, such as $11 \beta \mathrm{HSDH}$ or cytochrome $\mathrm{P} 450 \mathrm{c} 17 \alpha$, are alone sufficient to cause PCOS or whether other ovarian and/or adrenal factors play a role in the pathogenesis. In addition, the reason for the exaggerated corticoid excretion in the course of the nafarelin stimulation is in need of clarification.

\section{Acknowledgments}

The authors thank Mrs. C. Schoger for excellent technical assistance, Thanks are also due to Dr. H. M. P. Freie, Syntex Pharma, for providing us with Synarela.

\section{References}

1. Franks S, Adams J, Mason H, Polson D. 1985 Ovulatory disorders in women with polycystic ovary syndrome. Clin Obstet Gynecol. 12:605-632.

2. Goldzieher JW, Green JA. 1962 The polycystic ovary. I. Clinical and histologic features. J Clin Endocrinol Metab. 22:325-338.

3. Futterweit W, Dunaif A, Yeh HC, Kingsley P. 1988 The prevalence of hyperandrogenism in 109 consecutive female patients with diffuse alopecia. J Am Acad Dermatol. 19:831-836.

4. Conway GS, Honour JW, Jacobs HS. 1989 Heterogenity of the polycystic ovarian syndrome: clinical, endocrine and ultrasound features in 556 patients. Clin Endocrinol (Oxf). 30:459-470.

5. Franks S. 1989 Polycystic ovary syndrome: a changing perspective. Clin Endocrinol (Oxf). 31:87-120.

6. Barnes R, Rosenfield RL, Burstein S, Ehrmann DA. 1989 Pituitaryovarian reponses to nafarelin testing in the polycystic ovary syndromc. N Engl J Med. 320:559 565

7. Ehrmann DA, Rosenfield RL, Barnes RB, Brigell DF, Sheikh Z. 1992 Detection of functional ovarian hyperandrogenism in women with androgen excess. N Engl J Med. 327:157-162.

8. Chang RJ, Mandel FP, Lu JKH, Judd HL. 1982 Enhanced disparity of gonadotropin secretion by estrone in women with polycystic ovarian disease. J Clin Endocrinol Metab 54:490-494.

9. McKenna TJ. 1988 Pathogenesis and treatment of polycystic ovary syndrome. N Engl J Med. 318:558-562.

10. Rebar R, Judd HL, Yen SSC, Rakoff J, Vandenberg G, Naftolin F. 1976 Characterization of the inappropriate gonadotropin secretion in polycystic ovary syndrome. J Clin Invest. 57:1320-1329.

11. Yen SSC. 1980 The polycystic ovary syndrome. Clin Endocrinol (Oxf). 12:177-208.

12. Giagulli VA, Giorgino R, Vermeulen A. 1993 Origin and significance of plasma androsterone glucuronide levels: a parameter of adrenal androgen secretion and hepatic $5 \alpha$-reductase activity. J Clin Endocrinol Metab. 76:918-923

13. Rittmaster RS, Zwicker H, Thompson DL, Konok G, Norman RW. 1993 Androstanediol glucuronide production in human liver, prostate, and skin. Evidence for the importance of the liver in $5 \alpha$-reduced androgen metabolism. J Clin Endocrinol Metab. 76:977-982.

14. Stewart PM, Shackleton CHL, Beastall GH, Edwards CRW. $19905 \alpha$-reductase activity in polycystic ovary syndrome. Lancet 1:431-433.

15. Rodin A, Thakkar H, Taylor N, Clayton R. 1994 Hyperandrogenism in polycystic ovary syndrome. N Engl J Med. 330:460-465.

16. Rosenfield RL, Barnes RB, Cara JF, Lucky AW. 1990 Dysregulation of cytochrome P450c17 $\alpha$ as the cause of polycystic ovarian syndrome. Fertil Steril. 53:785-791.

17. Chrisp P, Goa KL. 1990 Nafarelin A review of its pharmacodynamic and pharmacokinetic properties, and clinical potential in sex hormone-related conditions. Drugs. 39:523-551.

18. Chaplin MD. 1992 Bioavailability of nafarelin in healthy volunteers Am J Obstet Gynecol. 166:762-765.

19. Sahin Y, Kelestimur F. 1993 17-Hydroxyprogesterone response to buserelin testing in the polycystic ovary syndrome. Clin Endocrinol (Oxf). 39:151-155.

20. Goldzieher JW. 1981 Polycystic ovarian disease. Fertil Steril. 35: 371-394.

21. Abraham GE, Maroulis GH, Buster JE, Chang RJ, Marshall JR. 1976 Effect of dexamethasone on serum cortisol and androgen levels in hirsute patients. Obstet Gynecol. 47:395-402.

22. Lobo RA. 1984 The role of the adrenal in the polycystic ovary syndrome. Semin Reprod Endocrinol. 2:251.

23. Hoffman DI, Klove K, Lobo RA. 1984 The prevalence and significance of elevated dehydroepiandrosterone sulfate levels in anovulatory women. Fertil Steril. 42:76-81.

24. Fox R, Corrigan E, Thomas PA, Hull MGR. 1991 The diagnosis of polycystic ovaries in women with oligo-amenorrhoea: predictive power of endocrine tests. Clin Endocrinol (Oxf). 34:127-131.

25. Robinson S, Rodin DA, Deacon A, Wheeler MJ, Clayton RN. 1992 Which hormone tests for the diagnosis of polycystic ovary syndrome? Br J Obstet Gynaecol. 99:232-238.

26. Burghen GA, Givens JR, Kitabchi AE. 1980 Correlation of hyperan- 
drogenism with hyperinsulinism in polycystic ovarian disease. $\mathrm{J}$ Clin Endocrinol Metab. 50:113-116.

27. Chang RJ, Nakamura RM, Judd HL, Kaplan SA. 1983 Insulin resistance in nonobese patients with polycystic ovarian disease. J Clin Endocrinol Metab. 57:356-359.

28. Dunaif A, Graf M, Mandeli J, Laumas V, Dobrjansky A. 1987 Characterization of groups of hyperandrogenic women with acanthosis nigricans, impaired glucose tolerance, and/or hyperinsulinemia. J Clin Endocrinol Metab. 65:499-507.

29. Dunaif A, Segal KR, Futterweit W, Dobrjansky A. 1989 Profound peripheral insulin resistance, independent of obesity, in polycystic nvary syndrome. Diabetes. 38:1165-1174.

30. Conway GS, Clark PMS, Wong D. 1993 Hyperinsulinaemia in the polycystic ovary syndrome confirmed with a specific immunoradiometric assay for insulin. Clin Endocrinol (Oxf). 38:219-222.

31. Haffner SM, Katz MS, Stern MP, Dunn F. 1988 The relation of sex hormones to hyperinsulinemia and hyperglycemia. Metabolism. 37: 683-688.

32. Peiris AN, Sothmann MS, Aiman EJ. 1989 The relationship of insulin to sex hormone binding globulin: role of adiposity. Fertil Steril. 52:69-71.

33. Invitti C, Giraldi FP, Dubini A, De Martin M, Cavagnini F. 1991 Increased urinary free cortisol and decreased serum corticosteroidbinding globulin in polycystic ovary syndrome. Acta Endocrinol (Copenh). 125:28-32.

34. Adams J, Polson DW, Franks S. 1986 Prevalence of polycystic ovaries in women with anovulation and idiopathic hirsutism. Br Med J. 293:355-359.
35. Matteri RK, Stanczyk FZ, Gentzschein EE, Delgado C, Lobo RA 1989 Androgen sulfate and glucuronide conjugates in nonhirsute and hirsute women with polycystic ovarian syndrome. Am J Obstet Gynecol. 161:1704-1709.

36. Giagulli VA, Giorgino R, Vermeulen A. 1991 Is plasma $5 \alpha$-androstane $3 \alpha, 17 \beta$-diol glucuronide a biochemical marker of hirsutism in women? J Steroid Biochem Mol Biol. 39:55-61.

37. Henzl MR. 1992 Gonadotropin-releasing hormone analogs: update on new findings. Am Obstet Gynecol. 166:757-761.

38. Shackleton CHL, Whitney JO. 1980 Use of Sep-Pak cartridges for urinary steroid extraction: evaluation of the method for use prior to gas chromatographic analysis. Clin Chim Acta. 107: 231-243.

39. Graef V, Fuchs M. 1975 Untersuchungen zur vollständigen enzymatischen Hydrolyse von Steroidkonjugaten im Harn. Z Klin Chem Klin Biochem. 13:163-167.

40. Schmidt NA, Borburgh HJ, Penders TJ, Weykamp CW. 1985 Steroid profiling-an update. Clin Chem. 31:637-639.

41. Egger HJ, Reiner J, Spiteller G, Heffele R. 1978 Harn Steroidprofile hirsuter Frauen. J Chromatogr. 145:359-369.

42. Rosenfield RL. $19905 \alpha$-Reductase and polycystic ovaries. Lancet. 1:1277.

43. Abraham GE, Chakmakjian ZH, Buster JE, Marshall JR. 1975 Ovarian and adrenal contributions to peripheral androgens in hirsute women. Obstet Gynecol. 46:169-173.

44. Lachelin GCL, Barnett M, Hopper BR, Brink G, Yen SSC. 1979 Adrenal function in normal women and women with the polycystic ovary syndrome. J Clin Endocrinol Metab. 49:892-898. 